This PDF is a selection from an out-of-print volume from the National Bureau of Economic Research

Volume Title: Risk Aspects of Investment-Based Social Security Reform Volume Author/Editor: John Y. Campbell and Martin Feldstein, editors

Volume Publisher: University of Chicago Press

Volume ISBN: 0-226-09255-0

Volume URL: http://www.nber.org/books/camp01-1

Publication Date: January 2001

Chapter Title: Can Market and Voting Institutions Generate Optimal Intergeneratic Risk Sharing?

Chapter Author: Antonio Rangel, Richard Zeckhauser

Chapter URL: http://www.nber.org/chapters/c10593

Chapter pages in book: (p. 113 - 152) 


\section{Can Market and Voting Institutions Generate Optimal Intergenerational Risk Sharing?}

Antonio Rangel and Richard Zeckhauser

We study economies confronted with generational risks. Such risks are shocks that affect all the members of a generation but have a smaller effect on other generations. They include the risk of having a bear market during the years one saves for retirement, being the age cohort that goes off to an extended war, or having one's prime employment years during a recession. With significant shocks of this sort, there are substantial benefits to intergenerational risk sharing. For example, young generations could insure the elderly against inadequate stock market performance. Indeed, precisely this risk-sharing measure has been discussed in the current debate on social security reform.

The central question of this paper is, Can market institutions or government actions generate efficient intergenerational risk sharing? Both markets and governments have the potential to promote risk sharing, markets through the trade of financial instruments, governments through social insurance programs. Each has potential on the intergenerational front since there are financial instruments that last for many generations and some social insurance programs, such as social security or subsidized education, transfer resources across generations. However, our analysis dashes hopes. We show that markets have problems generating optimal

Antonio Rangel is assistant professor of economics at Stanford University. Richard Zeckhauser is professor of political economy at the John F. Kennedy School of Government, Harvard University, and a research associate of the National Bureau of Economic Research.

The authors thank Peter Boasserts, John Campbell, David Cutler, Peter Diamond, Martin Feldstein, Peter Hammond, Matthew Jackson, Chad Jones, John Ledyard, Jeffrey Liebman, Marcos Lisboa, Greg Mankiw, Stephen Morris, Giussepe Moscarini, Thomas Nechyba, Ben Polack, Thomas Sargent, Chris Sims, Steve Tadelis, and participants in the Macro seminar at Harvard and Yale, the Public Economics seminar at Harvard, and the NBER preconference for their helpful comments. 
insurance and that self-interested voters may defeat government efforts to overcome market failures.

We use a simple endowment economy with uncertainty and overlapping generations to study the problem of intergenerational risk sharing. Each period there is uncertainty about the size of the aggregate endowment and its distribution between young and old. To see the role for intergenerational risk sharing, consider an extreme example in which the entire endowment goes either to the young or to the old. Absent a risk-sharing arrangement, agents consume nothing half the time, a woefully bad outcome. By contrast, a contingent claim or government program that transfers resources from young to old when the old get nothing, and vice versa, increases the welfare of every generation.

Optimality is a straightforward concept in deterministic economies but not in stochastic economies with overlapping generations. In the latter, at least two notions of optimality are frequently used: ex ante and interim efficiency. Both define Pareto improvements in the standard way - "a policy is Pareto improving if, and only if, it improves someone's welfare without hurting anyone else" - but differ on what the word anyone means. For the proponents of ex ante efficiency, identity is given solely by time of birth. Thus, an individual born in a given period but in two different states of the world is the same person. The advocates of interim efficiency disagree. For them, identity is given by time of birth and state of the world at birth. In the interim view, every generation has many different incarnations, and a policy can be Pareto improving only if it does not decrease the welfare of any of them. Many results in the literature on intergenerational risk sharing hold for one notion of optimality but not the other. Not surprisingly, there is spirited intellectual debate about which criterion is appropriate. We sidestep this debate and, like the rabbi in many a story, declare both sides correct. In particular, we show that both markets and voting institutions have difficulties generating desirable outcomes whether judged by ex ante or interim efficiency.

We start the analysis by establishing, as a benchmark, the intergenerational transfers that yield efficient outcomes. Clearly, efficient risk sharing would be achieved if a disinterested social planner orchestrated the transfers. But such a figure, however often invoked in economics, is chimerical. Efficient risk sharing will emerge only if it is generated endogenously by the institutions in our society. In other words, to determine what risk spreading will take place, we need to examine the intergenerational transfers that will be generated by markets and governments.

Among the market's finer achievements is its ability to spread risks in static economies. Financial assets, derivatives, and contingent claims are among the instruments that markets deploy as they reallocate risks to those who can bear them most cheaply. Should not such instruments, at least if the asset structure is rich enough, be able to spread risks optimally 
across generations? Alas not. First, since agents cannot trade before they are born, they cannot buy ex ante insurance. The aspiration level for markets is at best interim efficiency. Unfortunately, even this far lower hurdle presents problems. To understand why, it is useful to study markets with varying asset structures.

First, consider an economy with contingent commodities. Within it, agents facing the risk of a stock market collapse could insure themselves by purchasing contingent claims that pay off only given that eventuality. They could finance these purchases by selling contingent claims that pay off when the stock market booms. These trades provide valuable insurance because they shift consumption from high- to low-consumption states. However, with overlapping generations, trade takes place sequentially, and agents can trade only with coexisting generations, who face similar risks. As a result, these valuable trades do not take place.

Next, add an infinitely lived asset to this economy. The asset, call it money, pays no dividends and offers no consumption value. Infinitely lived assets are important because they generate intergenerational transfers when traded at positive prices. If prices fluctuate in the right way, these transfers even have the potential to generate efficient risk sharing. In fact, money generates interim efficient insurance in some, although not all, economies. Positively priced money generates backward transfers, those from young to old. Forward transfers can arise only if money trades at a negative price. But, in equilibrium, the price of money can never be negative since the older generation could simply destroy it rather than sell it. Thus, money can provide efficient risk sharing only when backward transfers are what is required. Unfortunately, many interesting generational risks, such as stock market risk, sometimes require transfers from old to young. Here, efficient risk sharing has the young help the old when the market drops but lets the young participate in the gains when the market booms.

Finally, consider an economy with a market mechanism that can generate forward transfers. This mechanism is a voluntary scheme in which each generation makes voluntary contributions during its youth and receives, as payoffs in old age, the contributions of the next young generation. ${ }^{1}$ Such an asset could be run by any infinitely lived institution and is in spirit an intergenerational Ponzi scheme. Here, unlike the case of money, nothing "real" is exchanged. Yet the two assets are extremely similar. Agents are willing to provide (invest in) them only if they believe that future generations will do the same. Since money pays no dividends and has no consumption value, agents will buy it only when they believe that their successors will do the same. Thus, there is always an equilibrium in which money

1. As far as we know, Demange and Laroque (1999) is the first publication describing this mechanism. 
has no value. Similarly, in the voluntary scheme, there is an equilibrium with zero contributions. In both cases, the value of the asset depends on self-fulfilling expectations. The only difference between them is that the voluntary system can generate negative contributions and thus forward transfers. As a result, with a voluntary pay-as-you-go mechanism, there is always an equilibrium that yields interim efficient risk sharing. However, as we argue later in the paper, this equilibrium is unlikely to arise.

These three institutions - contingent commodities, infinitely lived assets, and voluntary transfer mechanisms - represent the archetypal market structures that might generate efficient risk sharing. Since none of them works in all cases, it is natural to ask whether government policy can ride to the rescue. Obviously, a government acting as social planner could help by carrying out the transfers required for optimality. The government, after all, does have the power to transfer income across generations and thereby share risks efficiently. But the government's objectives are determined by political pressure, not by an innate desire to correct inefficiencies. Thus, the only interventions that are feasible are those that are desired by a majority of the voters.

A government with the power to carry out transfers between generations could use this power to implement optimal generational risk sharing. But it could also use it to carry out a selfish, purely redistributional policy. Voters, young and old, might choose to stick with the efficient risk-sharing rule, but they might vote to expropriate the other generation instead. Since old citizens die at the end of the period, they always favor imposing a big redistributive tax on the young. For example, even if the stock market boomed, they might favor taxing the young and, if in the majority, might vote that policy.

The young have different incentives, which may lead them to behavior that at least has a nobler cast. There are equilibria in which, even though they are in political control, the young implement an optimal risk-sharing rule that requires transfers to the elderly. They ascribe to what we label the golden transfer policy: transfer unto your predecessors as you would have your successors transfer unto you. Not only do the young refrain from expropriating the elderly, but they give actual transfers because they want to get equivalent transfers from the next generation of young voters. Thus, if the median voter is always young, as such a voter might be with consistent population growth, equilibria can readily emerge that offer efficient ex ante risk sharing, even when the immediate interest of the median voter would be to defect, indeed, to impose transfers in precisely the opposite direction.

Our applause should be restrained, however, since there is always another equilibrium at which the generations ignore risk-sharing considerations and expropriate each other to the extent that voting power and the Constitution allow. In this case, every generation is worse off than it would 
be with generational autarky, where the initial allocation prevailed and no transfers were possible.

The formal conclusions of this paper are dreary. The real world offers a somewhat brighter picture since the story of intergenerational overlap on which we rely is extreme, with lives lasting but two periods. If agents were to live for, say, seventy-five or more periods, both market and voting institutions would accomplish considerably more risk sharing. With just threeperiod lives, the young and the middle-aged generations can insure each other against the next period's risk since they will then be alive together. For example, the young might sell contingent claims against a stock market plunge, receiving in return some claims in case of boom. As overlaps expand, the market's performance improves, although full efficiency remains out of reach. Longer life spans will also tend to lure voters more toward cooperative behavior and less toward expropriation. Other features of the political landscape, for example, nongenerational concerns or risk sharing within generations, also have the ability to temper generational ruthlessness.

We conclude this introduction by relating our work to the existing literature. The main contribution of this paper is to take both market and political institutions seriously. There is a series of papers (see Bohn 1998; Enders and Lapan 1982; Fisher 1983; Gale 1994; Green 1977; Gordon and Varian 1988; and Smith 1982) that describe a range of circumstances under which market institutions produce insufficient risk sharing and thus leave open a role for Pareto-improving government interventions. Some of these papers use more realistic models of the economy, but, unlike ours, they do not study whether institutions that might overcome the inefficiency are feasible.

Obviously, our approach is also related to the literature on monetary equilibria in stochastic economies (see, e.g., Demange and Laroque 1998, 1999; Lucas 1972; Manuelli 1990; Muench 1977; and Peled 1982, 1984). However, there are important differences between the two approaches. We are interested in money as one of several mechanisms that might generate an optimal sequence of intergenerational transfers. In some sense, we follow a top-to-bottom approach. We first characterize the optimal transfers and then concentrate on specific institutions that might be able to generate them. By contrast, this literature follows a bottom-to-top approach. It considers the specific case of markets with money and shows that, whenever monetary equilibrium in which money trades at positive prices exists, it yields interim but not ex ante efficient risk sharing. Using our different approach, we show that money can fail to produce sufficient risk sharing, even when interim efficiency is the measuring rod.

Section 4.1 presents a model of the economy. Section 4.2 explores what might be meant by efficient risk sharing between generations. Section 4.3 introduces retirement risk as a specific form of generational risk, setting 
the stage to examine the risk-spreading performance of alternative institutions. Section 4.4 spotlights the strengths and vulnerabilities of market institutions as risk-sharing instruments. Section 4.5 gives parallel treatment to voting institutions. Section 4.6 concludes.

\subsection{A Model of the Economy}

Consider a simple overlapping-generations economy in which every period $t=0, \pm 1, \pm 2, \ldots$, a new generation $t$ is born and lives for two periods, $t$ and $t+1$. To focus on intergenerational risk sharing, suppose that there is only one agent per generation. Every period agents receive an endowment that depends on the state of the world $\theta$. This is a pure exchange economy, and the endowments cannot be stored. Thus, every period aggregate consumption equals the aggregate endowment. Let $e^{y}\left(\theta_{t}\right)$ denote the endowment of the young in period $t, e^{o}\left(\theta_{t}\right)$ the endowment of the old, and $E\left(\theta_{t}\right)$ the aggregate endowment. The set of states is finite, and the endowment process is independently and identically distributed (i.i.d.), with the probability of $\theta$ given by $\pi(\theta)$.

Each generation is born after that period's uncertainty is resolved. This assumption is important because it implies that young and old cannot enter into mutually beneficial risk-sharing agreements. After its birth, a generation faces uncertainty only in old age, and, since only future generations can insure them against this risk, there are no gains from trading with the elderly alive at the time.

The preferences of generation $t$ are given by

$$
u\left(c_{t}^{y}, c_{t+1}^{o}\right)=f\left(c_{t}^{y}\right)+f\left(c_{t+1}^{o}\right),
$$

where $c_{t}^{y}$ and $c_{t+1}^{o}$ denote, respectively, its consumption when young and in old age. We assume that $f$ is continuously differentiable, strictly concave, and increasing and satisfies $\lim _{x \rightarrow 0} f^{\prime}(x)=\infty$ and $\lim _{x \rightarrow 0} f(x)=-\infty$. These standard properties guarantee interior solutions to the maximization problems described below. The last two properties indicate a very strong desire for consumption smoothing since they imply that any amount of positive consumption in both periods is preferred to an allocation with zero consumption in either youth or old age.

An allocation is a function that specifies the consumption of young and old for any possible history of shocks. Given the purpose of our analysis and the nature of the model, we focus on stationary allocations in which consumption depends only on the current state of the world. In addition, feasibility requires that

$$
c^{y}(\theta)+c^{o}(\theta) \leq E(\theta) \text { for all } \theta .
$$

As we will see below, optimal intergenerational risk sharing requires carrying out intergenerational transfers between young and old that might 


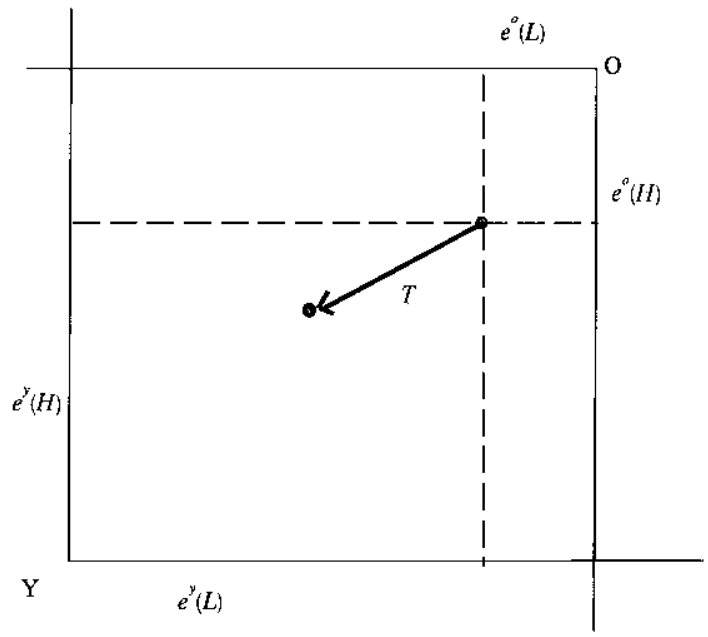

Fig. 4.1 Endowments of old and young in high and low states

depend on the state of the world. A risk-sharing rule is a function $T(\theta)$ that specifies the transfer from young to old in state $\theta$; negative values indicate transfers in the opposite direction. Clearly, a sharing rule generates allocations equal to

$$
c^{y}(\theta)=e^{y}(\theta)-T(\theta) \text { and } c^{o}(\theta)=e^{o}(\theta)+T(\theta) .
$$

Figure 4.1 gives a graphic representation of the economy that will be useful later on. The diagram is a variation of the well-known Edgeworth box. Consider an economy with only two states, high and low. The dimensions of the box are given by the size of the aggregate endowment, the low state on the horizontal axis, the high state on the vertical axis. A point in the box denotes how the endowment is distributed between young and old in each state. (The endowments of the old are measured from the upperright-hand corner.) For example, the central point represents a sharing rule in which young and old always consume the same amounts. Endowments and final allocations are denoted by points, risk-sharing rules by vectors.

\subsection{What Is Efficient Risk Sharing?}

The goal of this paper is to understand whether market and political institutions can generate optimal risk sharing. Hence, the analysis starts with a discussion of optimality. This notion is so widely used in economics that the reader might find it surprising that a discussion is needed at all. The problem is that, while the concept of optimality is straightforward in deterministic economies, the same is not true in stochastic models with 
overlapping generations. In fact, at least two alternative notions are frequently (and passionately) used: ex ante and interim efficiency. Both define Pareto improvements in the standard way- "a policy is Pareto improving if, and only if, it improves someone's welfare without hurting anyone else"-but differ on what the word anyone means. The disagreement is based on a different conception of identity. Is identity given solely by time of birth, or is it given by time of birth and the state of the world at birth? In other words, is an agent born in a given period but in different states of the world the same agent? For the proponents of ex ante efficiency, he is. The advocates of interim optimality disagree.

The disagreement carries over to the definition of optimality:

Definition 1. Ex ante optimality: A stationary allocation $c(\cdot)$ is ex ante Pareto optimal if there does not exist another feasible stationary allocation $\bar{c}(\cdot)$ such that for every generation $t$

$$
\sum_{\theta} \sum_{\hat{\theta}} \pi(\theta) \pi(\hat{\theta}) u\left(\bar{c}_{t}^{y}(\theta), \bar{c}_{t}^{o}(\hat{\theta})\right) \geq \sum_{\theta} \sum_{\hat{\theta}} \pi(\theta) \pi(\hat{\theta}) u\left(c_{t}^{y}(\theta), c_{t}^{o}(\hat{\theta})\right),
$$

with strict inequality for at least one generation.

DeFINITION 2. Interim optimality: A stationary allocation $c(\cdot)$ is interim Pareto optimal if there does not exist another feasible stationary allocation $\bar{c}(\cdot)$ such that for every generation $t$ and every state $\theta$

$$
\sum_{\hat{\theta}} \pi(\hat{\theta}) u\left(\bar{c}_{t}^{y}(\theta), \bar{c}_{t}^{o}(\hat{\theta})\right) \geq \sum_{\hat{\theta}} \pi(\hat{\theta}) u\left(c_{t}^{y}(\theta), c_{t}^{o}(\hat{\theta})\right),
$$

with strict inequality for at least one pair $(t, \theta)$.

In the ex ante view, since agents are able to compute expected utility before their birth, well-being is determined by the average welfare of their different incarnations. These averages have no meaning for the proponents of interim optimality. For them, consciousness and identity cannot precede birth, and, thus, when an agent is able to evaluate utility for the first time, he incorporates in his calculations all the information that he has at birth. As a result, he dislikes a policy that may have increased his welfare ex ante but decreases it in the particular state in which he is born.

An interim Pareto improvement is less likely to exist than an ex ante one. In the ex ante view, a Pareto improvement can occur when a generation wins in some incarnations, loses in others, but is better off on average. This is not interim Pareto improving, however, because it hurts some incarnations. As a result, every ex ante efficient allocation is also interim efficient, but not vice versa.

Which notion is the correct one? ${ }^{2}$ Clearly, the answer to this question

2. This question has been the subject of a long debate that started, at least, with the publication of Lucas (1972). Lucas proposed an ex post notion of optimality in which agents 
must be based on the merits of the notion, not on whether market or political institutions are able to generate that type of optimality. One must first select the optimality criteria and only then study which institutions are able to generate it.

Peled (1982) argues for interim efficiency because it mirrors the informational structure of the economy. In particular, it assumes that agents evaluate policy with the same information that they have when they trade in the market or when they vote: the young generation $t$ knows $\theta_{t}$ but not $\theta_{t+1}$. By contrast, the informational structure in the ex ante view has the flavor of a Rawlsian veil of ignorance in which agents evaluate policy before their birth.

This is a sound argument, but it is not sufficient to rule in favor of interim efficiency. If agents could travel out of time and trade before their birth, with knowledge about when they will be born but not about how uncertainty will be resolved, they would buy ex ante insurance. Thus, agents do not insure ex ante because they are technologically constrained (time travel not having been invented yet). But they would remove the constraint if they could find a way. In this view, the ex ante transfers can be seen as a way of removing the technological constraint. Agents would experience the technology as an improvement, and, as a result, they also view the ex ante transfers as Pareto improving.

Since both efficiency notions have significant standing and the goal of this paper is not to advocate for one or the other, we sidestep the debate by analyzing the risk-sharing properties of institutions under both points of view. As an added benefit, the reader might find that the analysis sheds light on the differences between them.

In the rest of this section, we characterize the set of optimal risk-sharing rules. Let us look first at ex ante optimality. The set of ex ante efficient stationary allocations is given as

$$
\max \sum_{\theta} \sum_{\hat{\theta}} \pi(\theta) \pi(\hat{\theta}) u\left(c^{y}(\theta), c^{o}(\hat{\theta})\right)
$$

subject to

$$
c^{y}(\theta)+c^{o}(\theta) \leq E(\theta) \text { for all } \theta .
$$

The properties of $f(\cdot)$ imply that the optimal allocation is uniquely determined by the first-order conditions

know how uncertainty is resolved throughout their lives. This notion is unsatisfactory because it rules out, by assumption, any gains from insurance. Muench (1977) pointed out these problems - which Lucas acknowledged in a reply (see Lucas 1977) — and proposed the ex ante and interim notions as an alternative. In a classic paper, Peled (1982) responded to Muench by forcefully defending interim optimality. The literature has used ex ante and interim notions ever since. 


$$
f^{\prime}\left(c_{\mathrm{EA}}^{y}(\theta)\right)=f^{\prime}\left(E(\theta)-c_{\mathrm{EA}}^{y}(\theta)\right),
$$

which imply the simple risk-sharing rule

$$
c_{\mathrm{EA}}^{y}(\theta)=c_{\mathrm{EA}}^{o}(\theta)=\frac{1}{2} E(\theta) .
$$

Thus, the ex ante optimal allocation is independent of how the endowment is distributed between young and old. As we will see in a moment, the same is true for interim efficient allocations.

Now look at interim optimality. Let $\gamma\left(\theta_{1}\right), \ldots, \gamma\left(\theta_{n}\right)$ be strictly positive weights satisfying $\Sigma \gamma(\theta)=1$. The set of interim efficient stationary allocations is given by the solution, for all possible weights, to ${ }^{3}$

$$
\max \sum_{\theta} \sum_{\hat{\theta}} \gamma(\theta) \pi(\hat{\theta}) u\left(c^{y}(\theta), c^{o}(\hat{\theta})\right),
$$

subject to

$$
c^{y}(\theta)+c^{o}(\theta) \leq E(\theta) \text { for all } \theta .
$$

Once more, we get that, for each vector of weights $\gamma(\cdot)$, the solution is fully and uniquely characterized by the first-order conditions

$$
\gamma(\theta) f^{\prime}\left(c_{\mathrm{IN}}^{y}(\theta)\right)=\pi(\theta) f^{\prime}\left(E(\theta)-c_{\mathrm{IN}}^{y}(\theta)\right) .
$$

The difference between the two sharing rules can be seen in figure 4.2. The dotted curve denotes the locus of interim efficient allocations. By contrast, the unique ex ante allocation is the point EA lying at the center of the box. Thus, for every endowment point, there is a unique ex ante efficient risk-sharing rule but many interim efficient ones.

We will see below that institutions have a harder time generating forward transfers, which go from old to young, than backward transfers, which go from young to old. Thus, it is important to identify the cases in which forward transfers are needed to restore efficiency. Figures 4.3 and 4.4 provide an answer to this question. The diagram in figure 4.3 can be used to describe both the economy with endowment $e$ and, by moving the endowment point around, the class of economies with that aggregate endowment. As figure 4.3 illustrates, the optimal ex ante risk-sharing rule requires a transfer toward EA, regardless of the endowment's location. Southwest movements indicate transfers from young to old, whereas northeast movements indicate forward transfers. We can see that the only economies in which ex ante efficiency can be restored using backward transfers are those to the northeast of EA. In other words, for a large class

3. This program yields an ex ante optimal allocation if, and only if, $\gamma(\theta)=\pi(\theta)$. This is another way of seeing that ex ante efficiency implies interim efficiency, but the opposite is not true. 


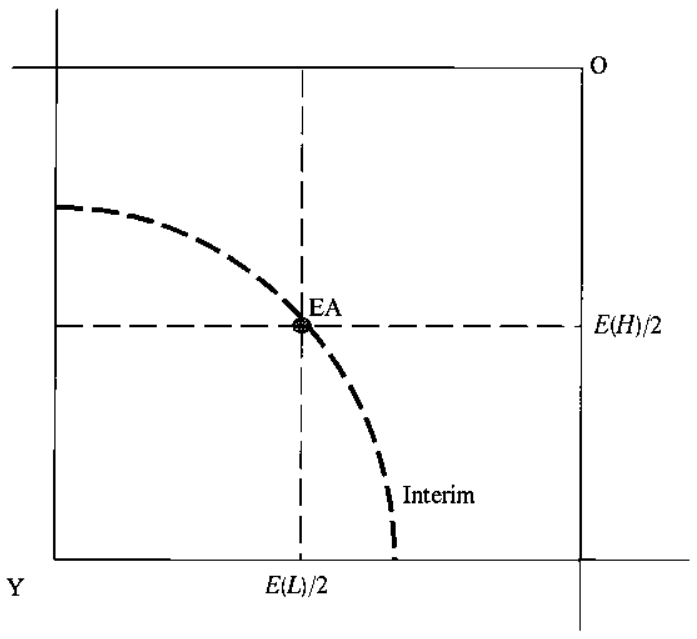

Fig. 4.2 Efficient risk-sharing rules

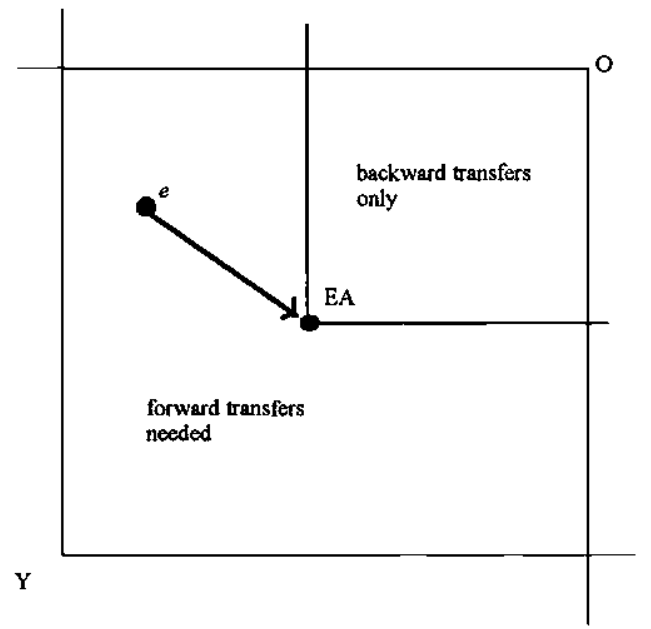

Fig. 4.3 Transfers that restore ex ante efficiency

of economies, optimal ex ante risk sharing requires the use of transfers from old to young in at least one state of the world.

In figure 4.4, we repeat the analysis for the case of interim efficiency. Since the set of efficient allocations has now increased, the problem is less severe. However, it is still the case that any economy to the southwest of the optimal locus must employ forward transfers to achieve an efficient outcome. Thus, as the diagram shows, forward transfers are needed under either criterion. 


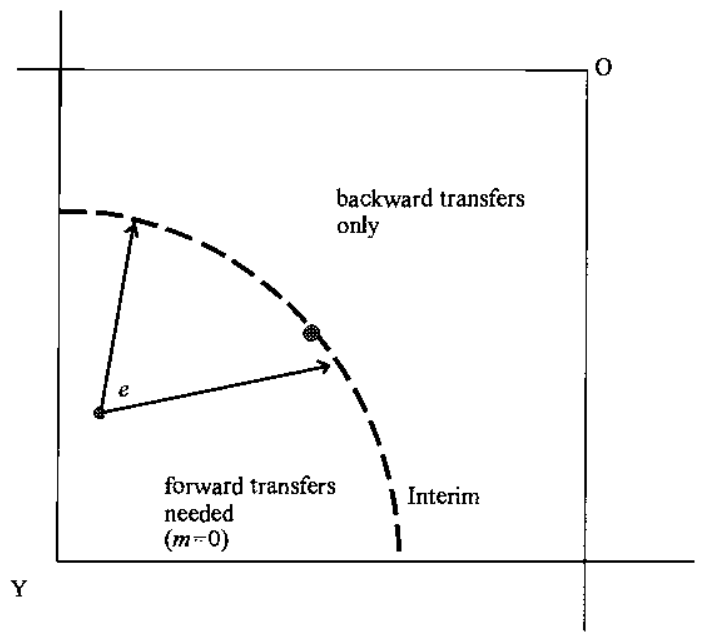

Fig. 4.4 Transfers that restore interim efficiency

Some of the results below follow from the fact that, in some economies, optimal risk sharing cannot take place without forward transfers. Clearly, these results are interesting only if this class of economies is empirically relevant. So, in practice, when are forward transfers likely to be necessary? As figure 4.4 illustrates, a sufficient condition is for the old to be significantly wealthier than the young in every state of the world. By contrast, forward transfers are not needed when it is the young who are wealthier, for example, when the elderly have no endowments in any state. In fact, some papers rule out the need for forward transfers by concentrating exclusively on the later case. The difference between our results and those in the previous literature can be attributed, in large part, to this restrictive assumption.

\subsection{Example: Retirement Risk}

The possibility of a stock market collapse and its effects on the welfare of retirees is an important issue in this volume and a prominent example of generational risks. For this reason, it is useful to look at an example that focuses precisely on this issue. Suppose that agents have a constant endowment when young but face uncertainty about their retirement income, which depends on stock market performance over their earning years. For concreteness, the stock market either collapses $(L)$ or booms $(H)$, with equal probability. This is represented by the endowment process $e^{y}(L)=e^{y}(H)=2, e^{o}(L)=1$, and $e^{o}(H)=4$. Agents' preferences are logarithmic. 
Aggregate output fluctuates widely; it is 3 in the low state and 6 in the high state. Furthermore, all the gains during booms accrue to the elderly, who also take all the losses during downturns. The efficient ex ante risksharing rule,

$$
T^{\mathrm{EA}}(L)=\frac{1}{2} \text { and } T^{\mathrm{EA}}(H)=-1
$$

is an intuitive arrangement in which the young insure the elderly against the downturn, for example, if the stock market collapses and, in return, the elderly share the windfall from bull markets.

It is worth emphasizing that this insurance arrangement differs significantly from the minimum-pension guarantees that are often discussed in the social security literature. First, this risk-sharing rule is two sided, as would be expected given that both generations bear risk. Retirees are protected against retirement risk, but they have to share the gains during booms. Second, the size of transfers depends on the entire state of the economy, not just on the performance of the stock market. This is an important feature because the cost of insuring the elderly depends on the income of the young. The young can insure the elderly only to the extent that their income remains relatively high during stock market collapses. In our example, this condition is satisfied; it is reflected in the relative size of the transfers.

This example also illustrates the differences between ex ante and interim efficiency. In the absence of any insurance arrangements, the expected utility at birth is 1.38 regardless of the state of the economy. The ex ante risksharing rule yields an average expected utility at birth, calculated of course before the agent is born, equal to 1.50 . But agents born in the low state have only 1.15 units of expected utility. Thus, they are happy to renege on the insurance arrangement.

\subsection{Market Institutions}

We have shown that efficient risk sharing requires intergenerational transfers and characterized the transfers that restore efficiency. But a social planner who could carry them out exists only in the scribblings of economists. Thus, efficient risk sharing can occur only if the transfers are generated endogenously by the institutions in the economy. This leads to the central question of this paper: Are there institutions capable of generating efficient intergenerational risk sharing? Two types of institutions are often suggested as possible solutions: markets and government. We study market institutions in this section and government intervention in the next and show that both have shortcomings as mechanisms for sharing risks between generations. 
Intuitively, one would expect the market to provide optimal insurance given a sufficiently rich asset structure in the economy. Although this intuition holds for static economies and even for dynamic economies with infinitely lived agents, it fails if there is limited overlap among generations. There are two reasons for this failure, the first straightforward, the second more subtle. The first problem is that agents cannot buy ex ante insurance since they can trade only after they are born. Thus, the market can provide at best interim insurance. The second problem presents a challenge even for this weaker notion of insurance. In an overlapping-generations economy, trade takes place sequentially. Each period, only the generations alive at the time can trade with each other. As we will see below, this restricts dramatically the amount of intergenerational risk sharing that takes place, even in economies with a rich asset structure.

To understand better the restrictions imposed by sequential trading and the role that different assets play in intergenerational risk sharing, this section studies three markets with different asset structures. First, we study markets with contingent claims. Next, we add an infinitely lived asset, like money, that pays no dividends but is sold from one generation to the next. Finally, we consider a new type of mechanism that resembles a voluntary pay-as-you-go social security system.

\subsubsection{Contingent Claims}

Consider an economy in which two types of commodities are exchanged every period: (1) that period's consumption good and (2) contingent claims for next period. Since trading takes place after the uncertainty has been resolved, prices might depend on the state of the world. Let $p(\cdot \mid \theta)$ denote the price of contingent commodities in state $\theta$, where $p(\hat{\theta} \mid \theta)$ buys one unit of next period's consumption if the state of the world turns out to be $\hat{\theta}$. We normalize the price of this period's commodity to 1 so that all contingent prices are real prices.

The equilibrium in this market is easily characterized. At any positive price, the elderly demand zero contingent commodities. If they could, they would sell short since they die at the end of the period and thus can default on their obligations. But we assume that short selling is not allowed. ${ }^{4}$ As a result, there are no intergenerational transfers in equilibrium. The price of the contingent claims adjusts so that the young demand exactly their endowment, no claims are exchanged, and no risk sharing takes place.

A young agent born in state $\theta$ faces the following market problem:

$$
\max f\left(c^{y}(\theta)\right)+\sum_{\hat{\theta}} \pi(\hat{\theta}) f\left(c^{o}(\hat{\theta})\right)
$$

4. This assumption is necessary, not only to get results that make sense, but also to get the existence of equilibrium. 
subject to

$$
c^{y}(\theta)+\sum_{\hat{\theta}} p(\hat{\theta} \mid \theta) c^{o}(\hat{\theta}) \leq e^{y}(\theta)+\sum_{\hat{\theta}} p(\hat{\theta} \mid \theta) e^{o}(\hat{\theta}) .
$$

Thus, the equilibrium vector of prices is given by

$$
p(\hat{\theta} \mid \theta)=\frac{\pi(\hat{\theta}) f^{\prime}\left(e^{o}(\hat{\theta})\right)}{f^{\prime}\left(e^{y}(\theta)\right)} \text { for all } \hat{\theta} .
$$

As we would expect, the price of contingent commodities is high for states in which the agent gets a poor outcome and low when he does well. For example, in the case of retirement risk, we get $p(L \mid H)=p(L \mid L)=1$ and $p(H \mid H)=p(H \mid L)=0.25$. At a price of four to one, agents facing the possibility of a stock market crash would choose no insurance. Thus, we have obtained the following result: ${ }^{5}$

Proposition. The market with contingent claims has a unique equilibrium in which no intergenerational transfers, and thus no risk sharing, take place.

One could think that the problem is due to market incompleteness, not the structure of sequential trading. After all, in our discussion, we included only one contingent commodity, whereas Arrow-Debreu markets have one contingent claim for every possible state and period. That would be incorrect. The result remains unchanged even if we introduce the entire set of contingent commodities.

The no-trade result, however, depends crucially on two other assumptions of the model. First is the assumption of one (representative) agent per generation. In a more realistic model with many agents and heterogeneity within generations, some trade would occur. However, all the trades would be between the members of the same generation. No intergenerational trade, and thus no intergenerational risk sharing, would take place. For this reason, and given the objectives of this paper, studying the oneagent case imposes no conceptual loss.

A more problematic assumption is that lives last for two periods. In a more realistic model in which agents live for seventy-five periods and with almost an equal number of overlaps, the trading of contingent commodities generates intergenerational transfers and thus risk sharing. To see why, consider the natural extension to three-period lives. Here, young and middle-aged agents face risks during the next period of their lives and can insure each other using contingent claims. It is natural to conjecture that the market efficiency increases with the number of overlaps and that it

5. Cass and Shell (1983) obtained a similar result, and Baxter (1989) contains an identical result. 
reaches 100 percent in the limit case of infinitely lived agents. As far as we know, however, this problem has not been solved.

\subsubsection{Contingent Claims and Infinitely Lived Assets}

Can an infinitely lived asset help overcome the problems that come from limited generational overlap? Consider an economy that, in addition to the contingent claims described above, has an infinitely lived asset that has neither productivity nor consumption value. Following Samuelson's (1958) classic paper, we refer to this asset as money. The introduction of money is valuable in this context because it generates intergenerational transfers when traded at a positive price and, as long as the prices fluctuate in appropriate fashion, it even has the potential to provide some intergenerational risk sharing.

Let $M$ be the amount of money in the economy and $m(\theta)$ its price in state $\theta$. Consider the market problem of an agent born in state $\theta$ :

$$
\max _{z(\cdot), \mu} f\left(c^{y}(\theta)\right)+\sum_{\hat{\theta}} \pi(\hat{\theta}) f\left(c^{o}(\hat{\theta})\right),
$$

subject to

$$
c^{y}(\theta) \leq e^{y}(\theta)-m(\theta) \mu-\sum_{\hat{\theta}} p(\hat{\theta} \mid \theta) z(\hat{\theta})
$$

and, for all $\hat{\theta}$,

$$
c^{o}(\hat{\theta}) \leq e^{o}(\hat{\theta})+m(\theta) \mu+z(\hat{\theta}) .
$$

These budget constraints can be rewritten as

$$
\begin{aligned}
c^{y}(\theta)+\sum_{\hat{\theta}} p(\hat{\theta} \mid \theta) c^{o}(\hat{\theta}) \leq & {\left[e^{y}(\theta)+\sum_{\hat{\theta}} p(\hat{\theta} \mid \theta) e^{o}(\hat{\theta})\right] } \\
& +\left[\sum_{\hat{\theta}} p(\hat{\theta} \mid \theta) m(\hat{\theta})-m(\theta)\right] \mu .
\end{aligned}
$$

In equilibrium, the following no-arbitrage condition holds in every state $\theta$ :

$$
\sum_{\hat{\theta}} p(\hat{\theta} \mid \theta) m(\hat{\theta}) \leq m(\theta) .
$$

Otherwise, agents could make a "profit" by selling $m(\hat{\theta})$ units of contingent claims in each market, using the proceeds to buy money that is used to service the claims, and keeping the difference. Thus, in equilibrium, the budget constraint reduces to

$$
c^{y}(\theta)+\sum_{\hat{\theta}} p(\hat{\theta} \mid \theta) c^{o}(\hat{\theta}) \leq\left[e^{y}(\theta)+\sum_{\hat{\theta}} p(\hat{\theta} \mid \theta) e^{o}(\hat{\theta})\right],
$$


and agents do not have a strict incentive to buy money. Agents can achieve the same amount of risk sharing buying contingent commodities. We will return to this issue later in the section.

Can money generate optimal risk sharing between generations? It has long been recognized that, since agents can trade only after they are born, money cannot generate ex ante risk sharing. However, there exists a large literature in macroeconomics (see, among others, Peled 1982, 1984; Manuelli 1990; and Demange and Laroque 1998, 1999) that studies the interim efficiency of monetary economies. These papers study conditions under which an interim weak first welfare theorem (WFWT) can be established. The first welfare theorem (FWT) states that every market equilibrium is efficient. By contrast, the WFWT holds if there is always a market equilibrium that is efficient, even when there are other inefficient equilibria.

It is easily seen that this market institution cannot satisfy the FWT because there is always an equilibrium with $m(\theta)=0$ for all $\theta$. In this case, money might change hands, but no real resources are transferred, and thus no risk sharing takes place. The problem is that monetary equilibria depend on expectations. Since money pays no dividends and has no consumption value, agents are willing to buy it only if they believe that they will subsequently be able to sell it for a positive and profitable price.

However, the problem is even worse.

THEOREM. Both the ex ante and the interim WFWT fail for a market with contingent claims and money as its risk-sharing instruments.

This result derives from a very simple fact. In equilibrium, the price of money can never be negative. In a state with negative prices, the old would burn their money rather than sell it. Also, an equilibrium in which $m(\theta)$ $=0$ for some states and $m(\hat{\theta})>0$ for some other states cannot exist; that is because the young would have an infinite demand for money in the first class of states and markets would not clear. We can thus conclude that money trades at positive prices in any equilibrium that generates intergenerational transfers. But this implies that, although money can generate either no transfers or backward transfers, it can never produce transfers from old to young. As a result, as figure 4.4 shows, the interim WFWT fails because all the economies in the southwest part of the box need forward transfers to restore efficiency. In fact, these economies have a unique equilibrium in which money has no value. Since ex ante efficiency implies interim efficiency, this argument also establishes the failure of the ex ante WFWT.

At face value, this theorem seems to contradict results in the previous literature that prove that any equilibrium in which money trades at nonzero prices is interim efficient. But there is no contradiction. As figure 4.4 shows, the problem is that equilibria with positive money prices might not exist. In those economies, the market cannot generate even efficient in- 
terim risk sharing. ${ }^{6}$ As we discussed before, forward transfers are not necessary if one assumes that the endowment process is to the northeast of the interim efficient frontier. This assumption is made in several papers in the literature.

The failure of the WFWT depends crucially on forward transfers being necessary for interim efficient risk sharing. Thus, it is important to ask whether any of our assumptions are essential for this effect. In particular, one might be suspicious of the lack of an initial period in our economy. Recall that $t=0, \pm 1, \pm 2$. . After all, if the economy is truncated at $t=0$, the risk-sharing policy depicted in figure 4.4 is not interim Pareto improving. Here, the elderly at time 0 make transfers without receiving anything in exchange.

To explore this issue, consider a variation of our model in which there is an initial generation born at time 0 , and suppose, as before, that the endowment process is characterized by a point in figure 4.4. If the endowment lies to the northeast of the interim frontier, then backward transfers are enough to restore interim efficiency, and the interim WFWT holds. Thus, suppose that the endowment lies to the southwest of the frontier, the case that causes problems in our model. The existence of a first generation changes the set of interim efficient allocations. To see why, consider the lower-left-hand corner of the box, an endowment process in which the elderly always get everything. The endowment allocation is interim efficient in the truncated economy because it gives the maximum feasible consumption to generation 0 . Thus, the interim WFWT trivially holds for this economy. Similarly, we conjecture that the interim WFWT holds for all the other truncated economies in this region.

It is important to emphasize, however, that interim efficiency holds because the existence of an initial generation makes Pareto improvements difficult, not because the market is generating the "right" intergenerational transfers. As before, there are risk-sharing rules that use forward transfers and make every generation, except the first one, better off. Therefore, the main insight generalizes to the case of economies with an initial generation: the interim efficient risk-sharing arrangements that everyone but the first generation favors cannot, in general, be generated by the market.

To understand better the differences between ex ante and interim insurance, it is useful to revisit the example of retirement risk. Figure 4.5 depicts the nontrivial monetary equilibrium that arises in this case. Money prices are $m(L)=m(H)=m=0.4435$. Thus, the trading of money restores interim efficiency, but it generates constant backward intergenerational transfers. From the ex ante point of view, this arrangement is quite coun-

6. Demange and Laroque (1999) allow money to take negative prices, and thus they are able to obtain a WFWT. The explanation is that their "negative money" resembles more the voluntary pay-as-you-go system studied in the next subsection than standard fiat money. 


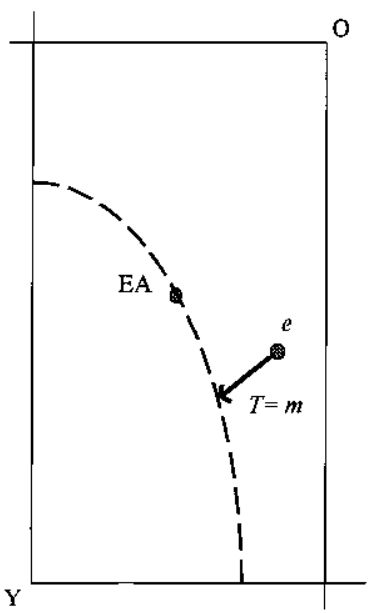

Fig. 4.5 Equilibrium with money

terintuitive. With money, the young always make a transfer to the old, which insures the old against the possibility of a stock market collapse. But, in contrast to ex ante risk sharing, the old do not share any of the gains from a stock market boom. In fact, since

$$
c^{o}(L)=\frac{1}{2}+m \text { and } c^{o}(H)=4+m
$$

the old end up consuming more in both states of the world.

\subsubsection{Voluntary Pay-as-You-Go Mechanisms}

The key problem with money as a risk-sharing mechanism is that it cannot generate forward transfers. In this section, we study a market mechanism that can. A voluntary pay-as-you-go system is basically an intergenerational Ponzi scheme in which each generation makes voluntary contributions during its youth and receives, as payoffs in old age, the voluntary contributions of the next generation. Such a mechanism could be run by an infinitely lived institution, for example, the government.

The return from investing in this asset is proportional to the aggregate contributions of the next generation and inversely proportional to the aggregate contributions of the present generation. Consider the market problem of an agent born in state $\theta$. If we let $\tau(\theta)$ denote aggregate contributions, the return on investing one unit is $\tau(\hat{\theta}) / \tau(\theta)$ when tomorrow's state is $\hat{\theta}$. Thus, the agent solves

$$
\max _{z(\cdot), \alpha} f\left(c^{y}(\theta)\right)+\sum_{\hat{\theta}} \pi(\hat{\theta}) g\left(c^{o}(\hat{\theta})\right),
$$


subject to

$$
\begin{aligned}
c^{y}(\theta)+\sum_{\hat{\theta}} p(\hat{\theta} \mid \theta) c^{o}(\hat{\theta}) \leq & {\left[e^{y}(\theta)+\sum_{\hat{\theta}} p(\hat{\theta} \mid \theta) e^{o}(\hat{\theta})\right] } \\
& +\left[\sum_{\hat{\theta}} p(\hat{\theta} \mid \theta) \tau(\hat{\theta})-\tau(\theta)\right] \frac{\alpha}{\tau(\theta)},
\end{aligned}
$$

where $\alpha$ is his contribution to the asset. The agent is a price taker, and thus he takes the "price" of the asset, or, more precisely, the aggregate contributions, as given.

As in the case of money, agents are willing to invest only if they believe that future generations will do the same. Thus, there is always an equilibrium in which $\tau(\theta)=0$ for all $\theta$ and no risk sharing takes place. This suggests that money and voluntary pay-as-you-go systems are very similar assets, even though in the latter case no "commodity" or piece of paper is exchanged. This is not surprising because the value of both assets depends on self-fulfilling expectations.

A careful examination of the budget constraints (6) and (4) shows that the two assets are almost identical. To see why, suppose that $M=1$ so that there is only one unit of money in the economy. In this case, $\mu$ denotes the share of the money supply that the agent is willing to hold, and, in equilibrium, we must have $\mu=1$. Similarly, in (6), $\alpha / \tau(\theta)$ denotes the share of contributions that the agent is willing to make, and, in equilibrium, $\alpha=\tau(\theta)$. But this implies that, as long as $m(\theta)=\tau(\theta)$ for all $\theta$, the two assets are identical, and we have the following result:

Proposition. If contributions cannot be negative, then there is a oneto-one correspondence between the equilibria in the market with money and the equilibria in the market with a voluntary pay-as-you-go mechanism.

In common parlance, a market economy with money and a voluntary pay-as-you-go social security scheme can achieve precisely the same outcomes. But what if we allow the young generation to extract resources from the social security scheme rather than pay into it? This enables the pay-as-you-go scheme to generate the forward transfers that are needed to restore interim efficiency, a capability not available to the market economy with money:

THEOREM. If negative contributions are possible, an economy with a voluntary pay-as-you-go mechanism can satisfy the interim WFWT but not the ex ante one. ${ }^{7}$

How should we interpret a negative contribution? Strictly speaking, it is a loan in which the cost of borrowing is determined by the actions of 
the next generation. Suppose that today's young generation contributes $-T$ to the system and that the next generation also contributes $-T$. Then the asset amounts to a loan with an interest rate equal to 1 . On the other hand, the loan is free if the next generation decides to contribute 0 .

It is important to emphasize that, with unrestricted contributions, a generation that buys the asset could find itself with an arbitrarily large liability. In a voluntary pay-as-you-go system, the "dividend" that the asset pays is determined by the actions of the next generation, which could decide to borrow an arbitrarily large amount. Of course, such behavior does not take place in equilibrium because the next generation would do the same, but such an action is a possibility. This is particularly problematic since, as we saw in (5), in equilibrium the price of the contingent commodities is such that agents do not have a strict incentive to buy the asset. So why should they take the risk? Thus, the equilibrium with $\tau(\theta)$ $=0$, and no risk sharing, is more plausible than the equilibrium with negative prices.

We can conclude that these archetypal market institutions cannot generate ex ante efficient risk sharing and are unlikely to generate interim efficiency, at least for a large class of economies. Can government policy come to the rescue?

\subsection{Voting Institutions}

The government has the power to transfer income across generations and thus to provide risk sharing. However, its objectives are determined by political pressure, not by an innate desire to correct inefficiencies. Thus, the problem with government, unlike the market, is not what it has the power to do but what it is likely to do given its power. In this section, we characterize the risk-sharing rules that arise as the result of the electoral process that guides government.

Each period there is an election in which all the agents alive at the time vote. Although many issues are decided in a typical election, here we model only the choice of intergenerational redistribution. The policy space in state $\theta$ is given by

$$
P(\theta)=\left\{T:-e^{o}(\theta) \leq-\underline{R}(\theta) \leq T \leq \bar{R}(\theta) \leq e^{y}(\theta)\right\},
$$

where $T$ is the transfer from young to old that is implemented in the period and $[-\underline{R}(\theta), \bar{R}(\theta)]$ are exogenously given constitutional constraints on intergenerational expropriation. We assume that $-R(\theta)<0<\bar{R}(\theta)$ so that both forward and backward transfers are possible. Clearly, efficient risk sharing arises only if voters always choose the optimal transfer $T^{*}(\theta)$ that we characterized in section 4.2 above.

Every period the young choose policy with probability $\lambda$ and the old with probability $1-\lambda$. We refer to the generation choosing policy as the 
median voter. If $\lambda=1$, the young always choose policy, for example, in an economy with a rapidly growing population, whereas, if $\lambda=0$, the old always determine policy, for example, when the old are well organized politically (e.g., through AARP). The model implicitly assumes that voters' preferences are determined by age. Although this assumption is not a good description of voting behavior for a wide range of issues (e.g., abortion or school prayer), it seems justified for intergenerational redistribution, where the effect that the policy has on an agent depends only on his age (for evidence in this regard, see Poterba [1997]).

Given these assumptions, the voting institution can be modeled as the following infinitely repeated game:

- Every period $t$, nature selects $\theta_{t}$ and chooses the identity of the median voter.

- After observing these outcomes, the median voter chooses a policy $p_{t}$ $\in P\left(\theta_{t}\right)$.

- There is complete information about the history of previous policies and states. History at time $t$ is denoted by

$$
h_{t}=\left(\ldots, \theta_{t-2}, \theta_{t-1}, \ldots, p_{t-2}, p_{t-1}\right) .
$$

- The set of political equilibria is given by the set of sequential equilibria of this game.

Let $p^{o}(\theta, h)$ denote the policy that an old median voter selects in state $\theta$, given history $h$. Define $p^{y}(\theta, h)$ similarly. Strictly speaking, voters have only one decision to make: how much to transfer between young and old. However, in order to understand better the politics of intergenerational risk sharing, it is useful to think of the policy space as having two dimensions:

$$
P(\theta) \subseteq\left\{I: I=T^{*}(\theta), 0\right\} \times\{R:-\underline{R}(\theta) \leq R \leq \bar{R}(\theta)\},
$$

that is

$$
p(\theta)=\left\{T^{*}(\theta), 0\right\}+R(\theta) .
$$

The first dimension, $I \in T^{*}(\theta)$, 0 , measures whether the efficient risksharing transfer is taking place. The second dimension, $R \in[-R(\theta)$, $\bar{R}(\theta)$ ], measures the amount of pure intergenerational redistribution. This representation emphasizes an important feature of the political process: once the door is open to carry out transfers between the generations, voters can choose optimal risk sharing, but they can also choose expropriation. Take, as an example, the case of retirement risk, and suppose that the median voter is always old. When the stock market collapses, these voters can tax the young and vote a minimum pension to themselves, as 
efficiency considerations demand. But they can also raise the taxes of the young in the case of a boom where, following the dictates of ex ante risk sharing, they are supposed to tax themselves.

The first step in analyzing the model is to note that an old median voter always chooses no risk sharing and maximum redistribution:

$$
p^{o}\left(\theta, h_{t}\right)=\bar{R}(\theta) .
$$

Since the elderly are not affected by future policy, their best option is to maximize current consumption, and, given the opportunity, they expropriate the young. From their point of view, the choice of taxes is purely about redistribution, not about risk sharing; after all, they do not face any more risks. Thus, we can interpret the vote of the elderly as a decision not to carry out any risk sharing and to expropriate the young as much as possible. In the expanded version of the game, this can be written as

$$
\tilde{p}^{o}\left(\theta, h_{t}\right)=(0, \bar{R}(\theta))
$$

What about young voters? As was the case with the market, the equilibrium of this model depends on the beliefs that present generations have about the behavior of future generations. There are, thus, two types of outcomes: Markovian equilibrium, in which no risk sharing takes place, and non-Markovian equilibrium, with optimal risk sharing.

In a Markovian equilibrium, agents maximize their payoff for the period because they believe that their actions do not affect the behavior of future voters. In this case, the young also expropriate as much as possible:

$$
p^{y}\left(\theta, h_{t}\right)=-\underline{R}(\theta) \text {. }
$$

As before, we can interpret their vote as a decision to focus purely on redistributive politics, without any concern for risk sharing $\left(\tilde{p}^{y}\left(\theta, h_{t}\right)=\right.$ $(0,-R(\theta)))$.

We can conclude that, in a Markovian equilibrium, every generation expropriates the others as much as possible and that the direction of expropriation depends on who ends up as the median voter. It is important to emphasize that, when there are few constraints on expropriation, for example, if $R(\theta)=e^{o}(\theta)$ and $\bar{R}(\theta)=e^{y}(\theta)$, agents are worse off here than with generational autarchy, where no risk sharing takes place.

There are also non-Markovian equilibria in which the young voters implement the optimal risk-sharing policy and resist the temptation of expropriating the elderly. Consider, for example, the following strategy:

$p^{y}(\theta, h)=$

$\begin{cases}T^{*}(\theta) & \text { if, at } h, \text { all the previous young median voters chose } T^{*}(\theta) ; \\ -\underline{R}(\theta) & \text { otherwise. }\end{cases}$ 
Here, optimal risk sharing takes place as long as every previous young generation has done the same. But, if there is any deviation from this behavior, they revert to the short-sighted expropriation strategy $(0,-\underline{R}(\theta))$. Cooperation does not depend on the behavior of the old since everyone knows that they always vote for expropriation. Using strategies of this type, we can establish the following result:

THEOREM. (1) If there are no limits to intergenerational expropriation $\left(\underline{R}(\theta)=e^{o}\right.$ and $\left.\underline{R}(\theta)=e^{y}(\theta)\right)$, then there are political equilibria in which the optimal (ex ante or interim) risk-sharing rule is implemented whenever the median voter is young. (2) Thus, if the median voter is always young $(\lambda=1)$, there are equilibria that generate both interim and ex ante efficient risk sharing. (3) However, regardless of who is the median voter, there is always an equilibrium in which there is no risk sharing, and full expropriation takes place.

The proof of this theorem reveals the essence of the problem. As we discussed above, the elderly always expropriate as much as possible. Thus, to check that the strategies (7) and (8) are a political equilibrium, we only need to verify the incentives of the young, who make decisions in two types of situations: (1) histories in which every previous young generation followed the efficient risk-sharing policy and (2) histories in which there was a deviation from this code of behavior.

Consider the first case, and suppose that the state of the world is $\theta$. The young median voter knows that, if the next median voter is old, he will choose $\bar{R}(\theta)$. On the other hand, if the next median voter is young, he will copy the behavior that the young voter chooses today; that is, expropriation will trigger expropriation, whereas optimal risk sharing will maintain optimal risk sharing. Thus, if the agent chooses $T^{*}(\theta)$, his lifetime payoff becomes

$$
\begin{aligned}
f\left(e^{y}(\theta)-T^{*}(\theta)\right) & +\lambda\left\{\sum_{\hat{\theta}} \pi(\hat{\theta}) f\left(e^{o}(\hat{\theta})+T^{*}(\hat{\theta})\right)\right\} \\
& +(1-\lambda)\left\{\sum_{\hat{\theta}} \pi(\hat{\theta}) f\left(e^{o}(\hat{\theta})+\bar{R}(\hat{\theta})\right)\right\} .
\end{aligned}
$$

On the other hand, if he decides not to cooperate with the risk-sharing rule, he is better off expropriating the elderly as much as possible $(T=$ $-\underline{R}(\theta)$ ), reaping a payoff equal to

$$
\begin{aligned}
f\left(e^{y}(\theta)+\underline{R}(\theta)\right) & +\lambda\left\{\sum_{\hat{\theta}} \pi(\hat{\theta}) f\left(e^{o}(\hat{\theta})-\underline{R}(\hat{\theta})\right)\right\} \\
& +(1-\lambda)\left\{\sum_{\hat{\theta}} \pi(\hat{\theta}) f\left(e^{o}(\hat{\theta})+\bar{R}(\hat{\theta})\right)\right\} .
\end{aligned}
$$


Thus, he cooperates as long as

$$
f\left(e^{y}(\theta)-T^{*}(\theta)\right)+\lambda\left\{\sum_{\hat{\theta}} \pi(\hat{\theta}) f\left(e^{o}(\hat{\theta})+T^{*}(\hat{\theta})\right)\right\}
$$

is greater than

$$
f\left(e^{y}(\theta)+\underline{R}(\theta)\right)+\lambda\left\{\sum_{\hat{\theta}} \pi(\hat{\theta}) f\left(e^{o}(\hat{\theta})-\underline{R}(\hat{\theta})\right)\right\} .
$$

For $\lambda$ sufficiently large, the left-hand side is approximately equal to the interim expected utility ${ }^{8}$ generated by the risk-sharing policy $T^{*}(\theta)$. By contrast, the right-hand side gives the payoff, in expected-utility terms, of the Markovian equilibrium in which every generation expropriates as much as it can. Without bounds of expropriation, $\underline{R}(\theta)=e^{o}(\theta)$ and $\bar{R}(\theta)$ $=e^{y}(\theta)$, this payoff becomes

$$
f(E(\theta))+\lambda\left[\sum_{\hat{\theta}} \pi(\hat{\theta}) f(0)\right] .
$$

So we finally conclude that the young choose optimal risk sharing over expropriation since they have a strong desire for consumption smoothing $\left(\lim _{x \rightarrow 0} f(x)=-\infty\right)$.

Now consider the second type of history. According to (7) and (8), future voters will ignore the risk-sharing rule and expropriate a coexisting generation as much as possible. As a result, present voters have no incentive to refrain from expropriation, and they also choose $T=-\underline{R}(\theta)$.

An interesting property of the previous equilibrium is that young agents are willing to implement the optimal ex ante transfer even though they constitute a majority and vote only after they are born. Since part of the uncertainty has been revealed, agents might have an incentive to default from the risk-sharing rule. For example, in the case of retirement risk, agents born in the low state get a payoff of 1.15 with insurance and 1.38 without insurance. Yet the previous analysis shows that they are willing to give a transfer to the elderly when the stock market collapses.

In this example, the only reason why young voters are willing to help the elderly is that failure to do so would trigger an expropriation precedent that could hurt them in old age. A risk-sharing rule is interim individually rational if, regardless of the state in which the agent is born, it is better than the initial endowment. Since the ex ante insurance arrangement is not interim individually rational, the promise of future insurance is not enough incentive to go along with it. The required additional incentive is provided by the possibility of expropriation.

8. That is, the expected utility conditional on knowing that the state of the world at birth is $\theta$. 
Consider the problem of designing a constitution that specifies the rules of the political process. Can we modify the rules in a way that makes optimal risk sharing more likely and rules out the possibility of intergenerational expropriation? One important lesson from the previous analysis is that risk sharing is more likely if the young always choose policy. However, youth dominance is not enough. Given that the Markovian equilibria always exist, we are faced with a perverse trade-off. In order to avoid shortsighted expropriation, restricting the policy space to something like

$$
P(\theta)=\left\{T^{*}(\theta), 0\right\},
$$

where expropriation might be prohibited through, say, a constitutional amendment, seems desirable. In this case, each generation can choose only to implement the optimal transfer or to do nothing; it cannot expropriate. However, ruling out expropriation could prove detrimental:

Proposition. The voting institution with a restricted policy space $\left\{T^{*}(\theta), 0\right\}$ and in which the median voter is always young can support only risk-sharing rules that are interim individually rational. Thus, in general, it can generate interim but not ex ante efficient risk sharing.

The problem with restricting the policy space is that it supports only risk-sharing rules that are interim individually rational. A risk-sharing policy is interim individually rational if it does not decrease the expected utility of an agent, conditional on knowing the state of the world at birth. As the case of retirement risk illustrates, in most cases of interest this condition is not satisfied. Thus, we are left with a Hobson's choice: we can either go with a restricted policy space, which rules out extreme expropriation but also sacrifices ex ante insurance, or go with the unrestricted policy space, which generates optimal risk sharing and no expropriation in the good equilibrium but produces disastrous outcomes in the bad one. ${ }^{9}$

Can government intervention generate efficient intergenerational risk sharing? The government certainly has on paper the power to carry out the efficient policy. For example, in the case of retirement risk, it could help retirees by taxing the young when the stock market crashes and similarly tax the elderly when the market booms. However, our analysis suggests that, as long as government policy is determined by self-interested citizens' votes, intergenerational transfers will be driven more by redistributive politics than by risk-sharing considerations.

9. The political economy of ex ante insurance is very similar to the political economy of public investment in future generations. The necessary and sufficient conditions to get optimal investment in future generations are explored in detail in Rangel (1998). 


\subsection{Conclusions}

Our conclusions are not happy: neither market nor political institutions can be counted on to generate efficient intergenerational risk sharing. Reality may be less dreary since our stark results follow from the assumption of two-period lives. As lives extend, overlaps increase, and trade in contingent commodities generates useful risk sharing. Similarly, the incentives to expropriate diminish with longer lives. Thus, market and voting institutions may do better than in our models, but our main conclusion holds: neither can be relied on to restore full efficiency.

Our analysis here is positive. The goal is to understand whether and when existing institutional arrangements generate efficient risk sharing. Although our analysis applies to all generational risks, including wars and economic declines, in the context of this volume it is important to consider the implications of our analysis for the current debate on social security reform.

The first implication is that, since markets cannot generate optimal risk sharing, a system of individual accounts cannot produce an efficient allocation. In a market with a rich-enough asset structure, agents can buy a lot of insurance against events like a stock market crash, but not perfect insurance. The size of the efficiency loss is an open empirical question.

This inefficiency can be corrected only by a government policy that carries out transfers between young and old, with the size and direction of the transfers depending on the state of the world. Thus, a combination of private accounts and a contingent pay-as-you-go system, which is able to transfer income in both directions, in principle dominates the pure private system.

But the second major lesson of this paper casts doubt on turning that potential into reality. The political economy of intergenerational transfers - that is, the fact that generations have to vote for the transfers that are made-may prevent a politically responsive government from intervening successfully. In some extreme cases, it may impose expropriating transfers that reduce the welfare of every generation.

It is important to emphasize, however, that the possibility of market failure does not rule in favor of a purely private approach to social security. There are many government policies, besides risk sharing, that redistribute income between generations. Government debt and the choice of the tax base are two prominent examples. Medicare most directly transfers to the elderly. ${ }^{10}$ These dimensions are subject to the same redistributive

10. Arguably, Medicare should be considered in conjunction with social security as a significant transfer program from young to old. Medicare's trustees project that its expenditures will compose 6.5 percent of GNP by the middle of the next century. 
politics that we study in this paper. Thus, intergenerational expropriation can take place even if the government turns social security over to the private sector. The same elderly who would use risk sharing to expropriate the young during a stock market boom can use debt to achieve an identical goal. This paper shows that government policy may not be able to provide optimal insurance. It does not show, however, that intergenerational redistribution is higher when the government is involved in social security.

The lessons of our overlapping-generations model for efficiency can be distilled briefly. The risk sharing brought by market institutions is always welcomed but never sufficient. The government has the power to generate efficient risk sharing, but sometimes that power is deployed insufficiently or perversely.

\section{References}

Baxter, M. 1989. Money and market incompleteness in overlapping generations models. Journal of Monetary Economics 24:69-91.

Bohn, H. 1988. Risk sharing in a stochastic overlapping generations economy. University of California, Santa Barbara. Mimeo.

Cass, D., and K. Shell. 1983. Do sunspots matter? Journal of Political Economy 91, no. 2:193-227.

Demange, G., and G. Laroque. 1998. Optimal intergenerational risk sharing and capital accumulation. Département et Laboratoire d'Economie Théorique et Appliquée, Ecole Normale Superieure, Paris. Typescript.

- 1999. Social security and demographic shocks. Econometrica 67, no. 3 (May): 527-42.

Enders, W., and H. Lapan. 1982. Social security taxation and intergenerational risk sharing. International Economic Review 23:647-58.

Fisher, S. 1983. Welfare aspects of government issue of indexed bonds. In Inflation, debt, and indexation, ed. Rudiger Dornbusch and Mario Henrique Simonsen. Cambridge, Mass.: MIT Press.

Gale, D. 1994. The efficient design of public debt. In Financial innovation and risk sharing, ed. Franklin Allen and Douglas Gale. Cambridge, Mass.: MIT Press.

Gordon, R., and H. Varian. 1988. Intergenerational risk sharing. Journal of Public Economics 37:180-202.

Green, J. 1977. Mitigating demographic risk through social insurance. NBER Working Paper no. 215. Cambridge, Mass.: National Bureau of Economic Research.

Lucas, R. 1972. Expectations and the neutrality of money. Journal of Economic Theory 4:103-24.

- 1977. Reply to Muench, Polemarchakis, and Weiss. Journal of Economic Theory 15:351-52.

Manuelli, R. 1990. Existence and optimality of currency equilibrium in stochastic overlapping generations models: The pure endowment case. Journal of Economic Theory 51:268-94.

Muench, T. 1977. Efficiency in a monetary economy. Journal of Economic Theory $15: 325-44$. 
Peled, D. 1982. Informational diversity over time and the optimality of monetary equilibria. Journal of Economic Theory 28:255-74.

1984. Stationary Pareto optimality of stochastic asset equilibria with overlapping generations. Journal of Economic Theory 34:396-403.

Poterba, J. 1997. Demographic structure and the political economy of public education. Journal of Policy Analysis and Management 16:48-66.

Rangel, A. 1998. Forward and backward intergenerational goods. Stanford University. Mimeo.

Samuelson, P. 1958. An exact consumption-loan model of interest with or without the social contrivance of money. Journal of Political Economy 66, no. 6:467-82.

Smith, A. 1982. Intergenerational transfers as social insurance. Journal of Public Economics 19:97-106.

\section{Comment Thomas J. Sargent}

\section{The Questions}

The paper under discussion takes up an important issue from an interchange among Muench (1977), Lucas (1977), and Peled (1982): how to compare consumption allocations in an overlapping-generations economy. Rangel and Zeckhauser adopt Muench's proposed ex ante utility measure for comparing stationary allocations in overlapping-generations economies. Muench called it ET-PO (equal treatment-Pareto optimality). Equal treatment means stationarity (people experiencing the same random state at different times receive the same consumption allocation). Muench computed utility "prior to birth" by averaging utilities across all the states into which a person had a chance of being born.

The alternative to ET-PO is promoted by followers of Lucas (1977) and Peled (1982), who argued that the nonoptimality often detected by the ET-PO test has an obvious source in an information advantage of a planner over the decision makers and that it is too easily used to criticize good equilibria from a superior vantage point. Lucas $(1977,351)$ noted that, "in any general equilibrium model with differently endowed risk averse agents, many allocations which are Pareto optimal will not be if preendowment insurance markets are admitted.' Joining the spirit of Lucas's remark, Peled formulated the concept of conditional Pareto optimality, which is based on expected utilities conditioned on the same information that the agents have when they make decisions. Peled advocated conditional Pareto optimality because it uses an information structure that mirrors that possessed by decision makers. Peled went on to show that there always exists a conditionally Pareto-optimal competitive equilibrium,

Thomas J. Sargent is the Donald Lucas Professor of Economics at Stanford University, a senior fellow of the Hoover Institution, and a research associate of the National Bureau of Economic Research. 
sometimes with and sometimes without valued fiat money (depending on the parameters). Peled's model has a stochastic version of Samuelson's (1958) result for nonstochastic overlapping-generations models that it is possible for a single asset (government debt or fiat currency) to cure a failure of a (nonmonetary) competitive equilibrium to be Pareto optimal.

Which welfare criterion should we prefer, Muench's or Peled's? Rangel and Zeckhauser are more enthusiastic proponents of Muench's criterion than Muench himself. Muench embraced his measure halfheartedly: "I am not asserting that the ET-PO criterion for optimality is the appropriate one. It seems to imply that all future generations agree before history begins. How can this be democratically achieved?" (1977, 325). An accomplishment of Rangel and Zeckhauser's is to investigate Muench's question. They describe a voting system (a description of a list of voters, a sequence of voting dates, and a protocol for the objects to be voted on) that can attain the ET-PO criterion "democratically." But they seem not to like their voting system, partly because it has an implementation problem (in addition to the ET-PO equilibrium, another very bad allocation is also an equilibrium), partly because the choice set must be specified to allow bad out-of-equilibrium outcomes to support good equilibrium outcomes, and perhaps also partly because it is not democratic from the viewpoint of old people.

\section{Plan of This Comment}

I shall devote most of my Comment to empathizing with Rangel and Zeckhauser's sympathy for Muench's prebirth utility criterion. I would like to add some empirical ammunition to their case by departing from the details of their setup while embracing its spirit. I want to reinterpret and broaden the risks. My reinterpretation of those risks is designed to amplify the claim that the welfare issue that Rangel and Zeckhauser raise is quantitatively important.

\section{Rangel and Zeckhauser's Setup}

Rangel and Zeckhauser study market and political arrangements in a pure endowment, doubly infinite ( $t$ "starts" at $-\infty$ and "ends" at $+\infty$ ) horizon model with overlapping generations of two-period-lived people. People within a generation have identical endowments and preferences. Preferences are stationary in the sense that a person born at $t+j$ values time $t+j+k$ consumption in the same way that a person born at time $t$ values time $t+k$ consumption. Agents are endowed only with time-dated goods bearing the same dates that they are alive, and they care only about 
those same goods. At each date $t$, endowments of both young and old depend on the realization of a single random variable $\theta$ that takes discrete values $\left[\theta_{1}, \ldots, \theta_{n}\right]$ where $\operatorname{prob}\left(\theta=\theta_{i}\right)=\pi_{i}$.

Rangel and Zeckhauser restrict themselves to studying stationary allocations; that is, they depend only on $\theta$, not on calendar time. They propose to compare the Pareto efficiency of various allocations in terms of two different ideas of what identifies a person. Let $v(\theta)$ be the optimum value function for a young agent born in state $\theta$. Rangel and Zeckhauser study welfare measures based on utility comparisons with two possible datings: (1) the conditional on $\theta$ or "interim" optimum value $v(\theta)$ and (2) the prebirth or ex ante optimum value $E v=\Sigma_{i} \pi_{i} v\left(\theta_{i}\right)$.

By excluding heterogeneity within a generation, Rangel and Zeckhauser focus on intergenerational risk sharing. To emphasize the potential quantitative significance of the substantive issue that they are raising, I prefer to recast their discussion of the ex ante versus the interim welfare criteria in another setting, one that highlights intragenerational risk sharing. In Rangel and Zeckhauser's model, there are different types and risks to be shared only because people are born at different phases of the "business cycle" indexed by $\theta$. In longer-lived overlapping-generations models, Rangel and Zeckhauser point out that much, if not most, of such risk could probably be insured by trading a small number of assets. So it seems likely that the ex ante versus the conditional on type welfare distinction acquires more quantitative importance if we introduce within-generation heterogeneity across types.

\section{Coincident but Heterogeneous Agents}

Thus, consider instead the kind of environment to which Lucas alluded in the quotation reproduced above. Let there be a stable distribution of types of people, where a type is a permanent attribute that cannot be controlled and that affects earnings from labor. Even in a standard general equilibrium model with coincident life spans, the ex ante versus the conditional on type welfare issue arises: welfare comparisons depend on whether utilities are evaluated before or after types are determined. A standard (Arrow-Debreu) way to set things up would be to take types as realized and to permit trading of a complete set of history-dependent claims to consumption bundles. The coincident lifetime complete markets model satisfies the two fundamental welfare theorems for a welfare criterion based on conditional on type utilities. But, from the prebirth viewpoint of "persons" whose types are uncertain, a competitive equilibrium allocation would be dominated by allocations that get more sharing across types. Only if agents could trade "before birth" would the welfare theorems hold for this economy. 


\section{Insurance for Types with Very Low Labor Income}

Thinking about private arrangements for trading "before birth" requires a model with parents and children. Children cannot trade before their births, but their parents can and would often want to. Thus, consider any of a number of conditions that dramatically reduce earnings potential and that are realized at birth. I believe that private insurance for these conditions is not sold now. This is curious because many of these conditions are easy to verify and involve no moral hazard. I offer the following calculations as rough estimates of what such insurance would cost. The four conditions-autism, cerebral palsy, Down syndrome, and spina bifida-have the following incidences per ten thousand live births in the United States: 4.5, 20, 12.5, and 5. So take the probability of having one of them to be .0042 . With a stationary population, to purchase an annuity paying $\$ 50,000$ per year conditional on a child having one of these disorders would then cost a one-time payment of $\$ 4,200$ per child. ${ }^{1}$

My reaction to these figures is that such insurance seems cheap to provide. Why does private insurance not exist? Why is it not provided by the government or at least by the U.S. government?

\section{Prebirth Risk for Workers}

In terms of their earnings ability, the low or zero-earnings types of people just mentioned are extreme values from a distribution of types. Applied economists have adduced ample quantitative evidence for the importance of types characterized by unobserved abilities that are valued in the labor market. I shall mention a couple of sources for estimates that might help give quantitative content to the theoretical welfare distinction. Of course, because variations of ability in the range that we are now considering are much harder to disentangle from effort, they are more difficult to insure through private arrangements. I will return to this point below. But first let me give some numbers.

\section{Evidence from Twins Studies}

Behrman, Rosenzweig, and Taubman (1994) present evidence for substantial labor market-relevant endowment heterogeneity. They use observations on identical twins to identify the effect of individual-specific endowments on log earnings. They estimate that 27 percent of the variance of $\log$ earnings from labor is due to variance in individual-specific endowments. Behrman, Rosenzweig, and Taubman also discuss how some of these individual effects might be insured through sharing within families

1. I am capitalizing the per person cost of $\$ 210.00$ per year at an interest rate of 5 percent per year. 
or creating new family links through marriage. In particular, they discuss whether schooling and marriage serve to attenuate or reinforce the individual-specific effects on earnings. They estimate that schooling is allocated to reinforce, and marriage matches made to attenuate, the individual-specific effects.

\section{Fixed Effects in Income Dynamics}

Another kind of evidence for heterogeneity comes from the literature on quantitative long-lived overlapping-generations models. Storresletten, Telmer, and Yaron (STY) (1998) have constructed a numerical long-lived overlapping-generations model for analyzing some proposed social security reforms. ${ }^{2}$ In their model, agents receive an exogenous stochastic endowment sequence, which STY choose to match to labor income. (Like Rangel and Zeckhauser, STY abstract from labor-supply decisions.) Agents can save in the form of a small number of assets, including physical capital. Because their model is basically a life-cycle version of a precautionary savings model, STY want a realistic specification of the laborincome dynamics. To calibrate their model to the contemporary United States, they use (Panel Study on Income Dynamics (PSID) data on labor earnings to create a specification that captures both $(a)$ the personal laborincome dynamics and $(b)$ the dispersion of the cross-sectional laborincome distribution by age of workers. To capture both of these, STY use a model with fixed effects, that is, different types. We can use their estimates to calibrate the importance of "type" in determining labor-income variance.

Thus, STY use the following transitory-permanent fixed-effects statistical model for the substantial part of the log of labor earnings $u_{i t}$ of the $i$ th person at age $t$ that cannot be explained by education and various other control variables:

$$
\begin{gathered}
u_{i t}=\alpha_{i}+z_{i t}+\varepsilon_{i t}, \\
z_{i t}=\rho z_{i t-1}+\eta_{i t} .
\end{gathered}
$$

Here, $\varepsilon_{i t}, \alpha_{t}$, and $\eta_{i t}$ are each normally and independently distributed and with mean zero and variances $\sigma_{\varepsilon}^{2}, \sigma_{\alpha}^{2}$, and $\sigma_{\eta}^{2}$, respectively, and $|\rho|<1$. The model (1) makes $u_{i t}$ a mixture of a transitory piece $\varepsilon_{i t}$, a persistent piece $z_{i t}$, and a person-specific fixed effect $\alpha_{i}$. Through precautionary savings, an individual can self-insure much of the transitory and persistent components (at least if $\rho$ is sufficiently smaller than unity); the fixed effect cannot be self-insured after birth. Model (1) implies the following covariances:

2. I thank Amir Yaron for discussing with me aspects of the rough calculations reported below on the basis of the STY paper. 


$$
\begin{gathered}
\operatorname{var}\left(z_{i t}\right)=\rho^{2} \operatorname{var}\left(z_{i t-1}\right)+\sigma_{\eta}^{2}, \\
\operatorname{var}\left(u_{i t}\right)=\sigma_{\alpha}^{2}+\operatorname{var}\left(z_{i t}\right)+\sigma_{\varepsilon}^{2}, \\
\operatorname{cov}\left(u_{i t}, u_{i t-j}\right)=\sigma_{\alpha}^{2}+\operatorname{cov}\left(z_{i t}, z_{i t-j}\right), \\
\operatorname{cov}\left(z_{i t}, z_{i t-j}\right)=\rho^{j} \operatorname{var}\left(z_{i, t-j}\right) .
\end{gathered}
$$

To initialize (2b), STY assume that $\operatorname{var}\left(z_{i,-1}\right)=0$.

STY use samples drawn from the PSID to fit the parameters of this model. First, they use pooled time series to estimate $\rho, \sigma_{\varepsilon}^{2}$, and $\sigma_{\eta}^{2}$. Setting $\sigma_{\alpha}^{2}=0$, they use these parameters to compute the cross-sectional distribution of income by age: the theoretically computed cross-sectional dispersion (without the fixed effects) increases with age, but for all ages it is below the actual cross-sectional dispersion of adjusted income $u_{i t}$ calculated directly from the PSID data. This observation impels STY to add the fixed effect through $\sigma_{\alpha}^{2}$ and to adjust $\rho$ to match the cross-sectional distribution of $u_{i t}$. They attain the parameter values $\sigma_{\alpha}^{2}=.326, \sigma_{\varepsilon}^{2}=.005$, $\sigma_{\eta}^{2}=.019, \rho=.98$. With these parameter values, the model roughly reproduces the level, upward slope, and curvature of the empirical crosssectional income variance-age relation. These estimates of the variances imply a cross-sectional standard deviation of the log of income for the youngest workers of $\sqrt{.35}$; this implies that the variance of the level of income is approximately $\exp (.35)[\exp (.35)-1]=.5947$. The observed initial cross-sectional standard deviation of the level of income was $\$ 2,100$ (in 1968 dollars). (The mean level of income [per adult-equivalent members of household] was $\$ 3,300$.) Thus, to get comparable units for the STY study, it is appropriate to multiply their standard deviation by $2,100 / \sqrt{.5947}$ to convert it into 1968 dollars.

To assess the implication of these parameters for Rangel and Zeckhauser's issue of ex ante versus conditional evaluation of utility, we can use STY's specification to compute the variance of the expected present discounted value of $\exp u_{i t}$ defined as

$$
\mathrm{PV}=E \sum_{t=0}^{T} R^{-t} \exp u_{i t} .
$$

Here, $E$ is the mathematical expectation with respect to the distribution generated by process (2). The variance of (3) measures the lifetime labor income risk faced by an agent before he or she is born. Part of the variance of (3) comes from the fixed effect $\alpha_{i}$, with the remaining part coming from chance income variations realized during the lifetime. For STY's specification with $R=1.04$ and a working life of $T=45$ years, I compute that the standard deviation of (3) is $\$ 40,500$ (in 1968 dollars) and that 69 percent of the variance is due to the fixed effect $\alpha$. A standard deviation of $\$ 40,500$ is substantial compared to an estimate of the average present 
90-10 Quantile Ratio, After-Tax and -Transfer Personal Income

\begin{tabular}{lc}
\hline Country and Year & $P_{90}-P_{10}$ \\
\hline Finland, 1991 & 2.75 \\
Sweden, 1992 & 2.78 \\
Belgium, 1992 & 2.79 \\
Netherlands, 1991 & 3.05 \\
Germany, 1989 & 3.21 \\
France, 1984 & 3.48 \\
Canada, 1991 & 3.90 \\
United Kingdom, 1991 & 4.67 \\
United States, 1991 & 5.78 \\
\hline
\end{tabular}

value of income of $\$ 83,000$ (in 1968 dollars) that can be coaxed from STY's figures. Thus, the income variance is substantial, as is the fraction of it due to the fixed effect. The 69 percent portion of the variance due to the fixed effect would be weighed by Rangel and Zeckhauser's ex ante welfare criterion, not by the conditional criterion.

\section{Insurability of Working Types}

The diverse individual-specific effects of "abilities" described in the previous two sections are not observable and can be inferred only by sophisticated statistical procedures. It is therefore not surprising that the private market does not offer to insure them. However, at least implicitly, societies provide social insurance for them through tax and transfer schemes. If we assume that abilities are equally distributed across countries, after-tax and -transfer income distributions across countries provide hints about the variation of the magnitude of the social insurance against realization of ability. For various countries, table 4C.1 shows $90-10$ percentile ratios for measures of after-tax, after-transfer income. The data are from Smeeding (1998), who reports that the income data include rents and interest but exclude capital gains and various in-kind transfers. Smeeding conjectures that including in-kind transfers would make less equal countries still less equal. The figures in table 4C.1 confirm what is widely known: that there is substantially more sharing across types in Northern European countries than in the United States.

\section{Efficiency and Equality}

Rangel and Zeckhauser's model and my use of STY's statistics probably overstate the case for using the ex ante criterion. It is probably not a good idea to interpret the figures presented in table 4C.1 with a model with exogenous labor income. Work in the tradition of Shavell and Weiss (1979) points to worthwhile incentives that are sustained by unequal consumption distributions. Shavell and Weiss assume that labor market outcomes are partly the result of a worker's hidden actions. In making con- 
sumption outcomes depend on the history of observed labor market outcomes, Shavell and Weiss's planner spreads the consumption distribution over time to reward workers who probably are partly lucky and probably also taking more productive private actions. Thus, the ShavellWeiss unemployment-compensation designer uses risk and the worker's aversion to it to manage incentive problems. Wealth distributions that spread out during time as a way optimally to trade off risk and efficiency have emerged in a variety of models in this tradition (e.g., Green 1987; Phelan and Townsend 1991; and Thomas and Worrall 1990). The pure endowment economies under discussion here do not allow us to think about this issue.

\section{Welfare Criteria and Transition Issues}

Welfare criteria based on conditional versus ex ante expected utility answer different questions and so cannot be evaluated without regard to the question at issue. Similarly, welfare criteria like Muench's ET-PO that compare only stationary allocations address questions like, What kind of society operating forever according to stationary allocation rules would you like to be born into? The criteria must be adjusted to answer questions that by their nature compare nonstationary allocations. Thus, Storesletten, Telmer, and Yaron (1998) and others in the Auerbach and Kotlikoff (1987) tradition who seek quantitatively to compare alternative proposals to reform social security arrangements struggle to adopt a welfare criterion that appropriately weighs conflicting interests. For evaluating proposals to change preexisting arrangements, at a minimum we need an initial stationary equilibrium, a new terminal one, and a transition path between them. For analyzing transition issues, the most popular framework within the Auerbach-Kotlikoff tradition is the one-sided infinite-horizon economy studied by Samuelson and Peled, in which there is an initial old generation most of whose uncertainties have been resolved and who have entitlements that have to be respected in evaluating welfare. I recommend reading the paper by Storesletten, Telmer, and Yaron (1998) alongside Rangel and Zeckhauser's paper because of how they struggle to get as far as possible using an ex ante welfare criterion and stationary equilibria to analyze alternative reform proposals.

\section{References}

Auerbach, Alan J., and Laurence J. Kotlikoff. 1987. Dynamic fiscal policy. Cambridge: Cambridge University Press.

Behrman, Jere R., Mark R. Rosenzweig, and Paul Taubman. 1994. Endowments and the allocation of schooling in the family and in the marriage market: The twins experiment. Journal of Political Economy 102, no. 6:1131-74. 
Green, Edward J. 1987. Lending and the smoothing of uninsurable income. In Contractual arrangements for intertemporal trade (Minnesota Studies in Macroeconomics, vol. 1), ed. Edward C. Prescott and Neil Wallace. Minneapolis: University of Minnesota Press.

Lucas, Robert E., Jr. 1977. Reply to Muench and Polemarchakis and Weiss (1977). Journal of Economic Theory 15:351-52.

Muench, Thomas J. 1977. Efficiency in a monetary economy. Journal of Economic Theory 15:325-44.

Peled, Dan. 1982. Informational diversity over time and the optimality of monetary equilibria. Journal of Economic Theory 28:255-74.

Phelan, Christopher, and Robert M. Townsend. 1991. Computing multi-period, information-constrained optima. Review of Economic Studies 58, no. 5:853-81.

Samuelson, Paul. 1958. An exact consumption-loan model of interest with or without the social contrivance of money. Journal of Political Economy 66:467-82.

Shavell, Steven, and Laurence Weiss. 1979. The optimal payment of unemployment insurance benefits over time. Journal of Political Economy 87 (December): $1347-62$.

Smeeding, Timothy M. 1998. U.S. income inequality in a cross-national perspective: Why are we so different? In The inequality paradox: Growth of income disparity, ed. James A. Auerbach and Richard S. Bebous. Washington, D.C.: National Policy Association.

Storesletten, Kjetil, Chris Telmer, and Amir Yaron. 1998. The risk sharing implications of alternative social security arrangements. Carnegie-Mellon University. Mimeo.

Thomas, Jonathan, and Tim Worrall. 1990. Income fluctuation and asymmetric information: An example of a repeated principal-agent problem. Journal of Economic Theory 51, no. 2:367-90.

\section{Discussion Summary}

Henning Bohn made two remarks. First, he stated that the assumption of stationarity seems very critical in the context of interim efficiency: interim efficiency imposes no constraints whatsoever unless one operates in stationary environments. It seems, therefore, that the sharpness of the results of the paper hinges crucially on the stationarity assumption rather than on the efficiency concept used. Second, with respect to social security and policy issues, Bohn noted that, if one looks for some benchmark to judge different policies, then only ex ante efficiency would be a useful concept, especially if the government might affect the allocation (as opposed to exercises where the only uncertainty concerns the endowment).

Robert King remarked that some discussion of the public finance literature on the income tax might be useful: ultimately, a zero marginal tax rate is optimal, yet very few social institutions implement a marginal tax rate close to zero. The social security system is apparently one that does. Second, the fixed-effects coefficient $\alpha_{i}$ of Storesletten, Telmer, and Yaron to which the discussant, Thomas Sargent, refers could be the result of 
parental investments. Therefore, if one thinks about redistribution mechanisms in this context across individuals, one could be influencing the incentives that parents would have to make such investments.

Following up on King's remark, Amir Yaron commented on the variance decomposition of the present value of lifetime income reported in the Storesletten, Telmer, and Yaron paper and referred to by Sargent. Yaron noted that the fraction of the standard error of lifetime income due to the fixed-effects term $\left(\alpha_{i}\right)$ ranges from 0.4 to 0.75 , depending on the empirical procedure. Of course, even the lower bound of these estimates reveals the importance of individual fixed effects for someone's lifetime earnings potential. He agreed with King's remark about the relevance of education and therefore of parental investments.

Stephen Ross noted that there is a relation between the choice of efficiency and the choice of a model, going either backward or forward. If one considers, for example, a model that starts at a particular point, interim efficiency should not be achieved because, while it is possible to tax backward through a sufficiently high interest rate, one cannot tax forward. Ross further remarked that he found the concept of ex ante optimality or equal treatment Pareto efficiency disturbing as it treats cohorts to be born in the remote future in the same way as the generation currently alive. $\mathrm{He}$ stated that he strongly favored attaching a smaller weight to those remote generations than to the current one. He added that the concept is moreover politically infeasible.

$Z v i$ Bodie inquired whether the discussant knew why the insurance contracts he mentioned, insuring the risk of being born with illnesses that adversely affect the lifetime ability to earn income, are not being offered. He added that moral hazard was presumably not the reason. He concluded that it might be in the interest of insurance companies to offer these contracts.

Thomas Sargent elaborated on his discussion of the results of Behrman, Rosenzweig, and Taubman, documenting the importance of substantial labor market-relevant permanent-endowment heterogeneity. He noted that these authors also study the covariation of this innate ability with two other variables, education and marriage. They find that education acts to reinforce innate differences while marriage dampens them.

In response to the discussions and comments, Antonio Rangel made the following points. First, he noted that, although he often has strong opinions, this is not the case in the debate on the choice of the efficiency concept. The paper studies the performance of institutions under both efficiency criteria without in any way advocating the concept of ex ante efficiency. Second, with respect to Bohn's comment about the importance of the stationarity assumption, Rangel clarified that, while the stationarity assumption is innocuous, modeling time as doubly infinite is crucial for 
the results of the paper. In particular, the absence of any first generation is what drives many of the results, including the disagreement with the findings of Peled, as remarked by Sargent.

Finally, Rangel pointed out that the choice between the ex ante and the interim efficiency concept is often trivial, especially in static models. $\mathrm{He}$ gave examples of idiosyncratic or intragenerational risks where taking an ex post perspective is obviously meaningless. On the contrary, in the model presented in the paper, considering intergenerational risks instead, the choice is nontrivial, and both concepts are interesting alternatives.

Richard Zeckhauser noted that no forward or backward altruism is assumed in the model. Agents care only about themselves, except perhaps for strategic, game-theoretic reasons. 
